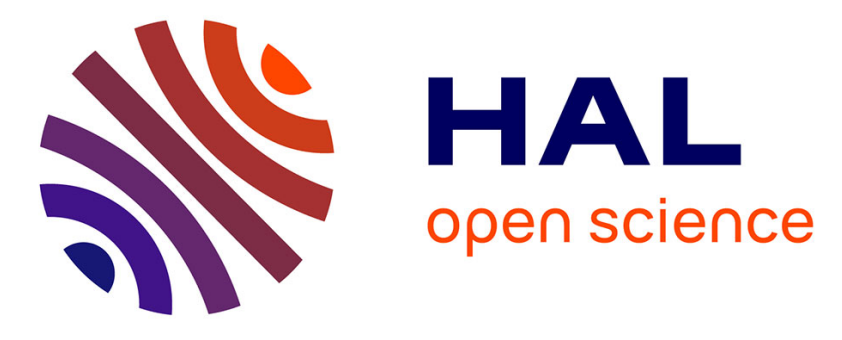

\title{
Protopathic bias in observational studies on statin effectiveness
}

\author{
Maarit Jaana Korhonen, Risto Huupponen, Päivi Ruokoniemi, Arja \\ Helin-Salmivaara
}

\section{- To cite this version:}

Maarit Jaana Korhonen, Risto Huupponen, Päivi Ruokoniemi, Arja Helin-Salmivaara. Protopathic bias in observational studies on statin effectiveness. European Journal of Clinical Pharmacology, 2009, 65 (11), pp.1167-1168. 10.1007/s00228-009-0701-0 . hal-00534983

\section{HAL Id: hal-00534983 \\ https://hal.science/hal-00534983}

Submitted on 11 Nov 2010

HAL is a multi-disciplinary open access archive for the deposit and dissemination of scientific research documents, whether they are published or not. The documents may come from teaching and research institutions in France or abroad, or from public or private research centers.
L'archive ouverte pluridisciplinaire HAL, est destinée au dépôt et à la diffusion de documents scientifiques de niveau recherche, publiés ou non, émanant des établissements d'enseignement et de recherche français ou étrangers, des laboratoires publics ou privés. 


\title{
Protopathic bias in observational studies on statin effectiveness
}

\author{
Maarit Jaana Korhonen • Risto Huupponen • \\ Päivi Ruokoniemi • Arja Helin-Salmivaara
}

Received: 30 June 2009 / Accepted: 3 July 2009 /Published online: 22 July 2009

(C) Springer-Verlag 2009

\begin{abstract}
A meta-analysis of 14 randomized controlled trials (RCT) of statins in prevention of major vascular events suggests that almost all diabetic patients benefit from statin therapy, with a $10 \%$ relative reduction in event rates for every millimole per litre reduction in low-density lipoprotein cholesterol seen in 1 year [1]. The results of the RCTs including only patients with diabetes are, however, inconclusive. For ethical reasons, long-term placebo-controlled RCTs of statins in diabetic populations are no longer possible. Therefore observational studies are an essential tool for future research [2], but they are prone to various biases. Protopathic bias occurring when the drug is preferentially prescribed to persons with early symptoms of the outcome under study is one of them [3].
\end{abstract}

\footnotetext{
M. J. Korhonen · R. Huupponen · P. Ruokoniemi ·

A. Helin-Salmivaara

Pharmacology, Drug Development and Therapeutics,

University of Turku,

20014 Turku, Finland
}

\section{J. Korhonen $(\square)$}

School of Public Health and Clinical Nutrition,

University of Kuopio,

POB 1627, 70211 Kuopio, Finland

e-mail: maarit.korhonen@utu.fi

\section{R. Huupponen}

Tykslab, Health Care District of Southwest Finland,

Turku, Finland

\section{P. Ruokoniemi}

Department of Clinical Pharmacology, University of Helsinki, Helsinki, Finland

\section{A. Helin-Salmivaara}

Unit of General Practice,

Hospital District of Helsinki and Uusimaa,

Helsinki, Finland
We evaluated the potential for protopathic bias in an observational study on cardiovascular benefits of statins in diabetes by examining the rates of major cardiac events (MCE) among statin initiators with diabetes, with a focus on the first year of therapy. Using a nationwide prescription-claims database maintained by the Social Insurance Institution of Finland [4], we identified 53,943 statin initiators (mean age, 62.0 years; $44.2 \%$ female) among community-dwelling patients with diabetes, aged 45-75, between January 1, 1995, and December 31, 2006. Initiators had no statin purchases in the year before the start of follow-up. MCEs included acute myocardial infarctions, subendocardial infarctions, and coronary revascularization procedures captured through the national hospital discharge register. The follow-up ended with the occurrence of an MCE, death, permanent institutionalization, or December 31, 2007, whichever came first.

During a mean of 4.0 years of follow-up, there were 6,270 hospitalizations for MCEs (2,370 for infarctions, 3,580 for revascularization procedures, 320 with both diagnoses) among patients with diabetes, corresponding to an incidence rate of 2.9 per 100 person-years. Almost half (46.4\%) of the events, however, occurred within 365 days of statin initiation, resulting in an incidence rate of 5.9 per 100 person-years during the first year. Of these early MCEs, $67.1 \%$ were coronary revascularization procedures. Monthly MCE rates, especially revascularization procedure rates, declined steeply, stabilizing by the ninth month of therapy (Fig. 1). The MCE rates during the first months of therapy were higher among statin initiators in 1995-1998 $(n=9,971)$ than among initiators in 2004-2006 $(n=17,668)$. This probably reflects the shift in statin initiators' baseline risk, as the proportion of initiators with coronary artery disease (CAD) decreased to 10.7 from $36.3 \%$ during the same period. 


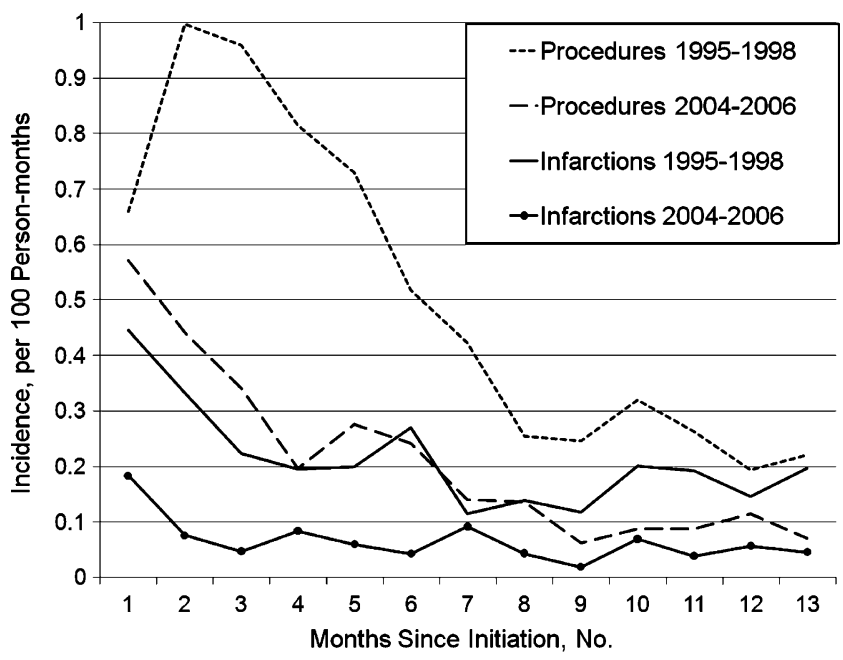

Fig. 1 Monthly incidence of hospitalizations for coronary revascularizations and infarctions among statin initiators with diabetes in Finland in 1995-1998 $(n=9,971)$ and in 2004-2006 $(n=17,668)$

Our findings imply that diabetic patients may receive their first statin prescription when they present with angina and are, in some cases, scheduled for a coronary revascularization procedure at the same time. Therefore the results of observational studies on statin effectiveness in preventing MCEs among diabetic patients may be distorted by protopathic bias if the initial months of follow-up are included in the analysis. This means also that the early benefits of statins [1] may not be validly studied in observational designs.

While supporting the use of lag-time or exclusion of a specific time period of follow-up after statin initiation $[3,5]$, our results suggest that the optimal lag-time for avoiding protopathic bias differs over time, in the Finnish context being under 1 year. Accordingly, in a recent Canadian study comparing the risk of $\mathrm{CAD}$ associated with various adherence levels ( $\geq 80 \%$ versus $<80 \%$ ), benefits of high statin adherence appeared to emerge before 1 year [6].

Overall, our findings highlight the need to consider not only the pathophysiology of the disease and the characteristics of the population under study, but also the health-care system through which the data are generated and the changes in it over time when designing observational studies on drug effectiveness and interpreting their results.

Acknowledgements This study was funded by a grant (October 26, 2007) from the Social Insurance Institution of Finland (M.J.K., A.H.-S., and P.R.).

\section{References}

1. Cholesterol Treatment Trialists' (CTT) Collaborators (2008) Efficacy of cholesterol-lowering therapy in 18686 people with diabetes in 14 randomised trials of statins: a meta-analysis. Lancet 371:117-125

2. Ligthelm RJ, Borzi V, Gumprecht J, Kawamori R, Wenying Y, Valensi P (2007) Importance of observational studies in clinical practice. Clin Ther 29:1284-1292

3. Tamim H, Monfared AA, LeLorier J (2007) Application of lagtime into exposure definitions to control for protopathic bias. Pharmacoepidemiol Drug Saf 16:250-258

4. Helin-Salmivaara A, Lavikainen $\mathrm{P}$, Korhonen MJ, Halava $\mathrm{H}$, Junnila SY, Kettunen R, Neuvonen PJ, Martikainen JE, Ruokoniemi P, Saastamoinen LK, Virta L, Huupponen R (2008) Long-term persistence with statin therapy: a nationwide register-based study in Finland. Clin Ther 30(Theme Issue):2228-2240

5. Smeeth L, Douglas I, Hall AJ, Hubbard R, Evans S (2009) Effect of statins on a wide range of health outcomes: a cohort study validated by comparison with randomized trials. $\mathrm{Br} \mathrm{J}$ Clin Pharmacol 67:99-109

6. Perrault S, Dragomir A, Blais L, Berard A, Lalonde L, White M, Pilon D (2009) Impact of better adherence to statin agents in the primary prevention of coronary artery disease. Eur J Clin Pharmacol. doi:10.1007/s00228-009-0673-0 